\title{
A case of iatrogenic severe mitral regurgitation
}

\section{Un caso di insufficienza mitralica severa iatrogena}

\author{
Antonio D’Aloia, Barbara Piovanelli, Riccardo Rovetta, Ivano Bonadei, \\ Enrico Vizzardi, Antonio Curnis, Marco Metra
}

\begin{abstract}
A case of iatrogenic severe mitral regurgitation. A. D'Aloia, B. Piovanelli, R. Rovetta, I. Bonadei, E. Vizzardi, A. Curnis, M. Metra.

Bromocriptine and cabergoline, ergot derived dopamine receptor agonists used to treat Parkinson's disease and prolactinomas, have been associated with increased risk of car-
\end{abstract}

diac valve disease. Here we present a case of iatrogenic symptomatic severe mitral regurgitation due to these drugs.

Keywords: valve disease, cabergoline, severe mitral regurgitation.

Monaldi Arch Chest Dis 2013; 80: 133-136. Deparment of medical and surgical, radiological sciences and public health specialty, Section of Cardiovascular Diseases,
University of Study of Brescia.

Corresponding author: Riccardo Rovetta; Piazzale Spedali civili 1, I-25100 Brescia, Italy; Tel.: +39030 399575, Fax: +39030 3995018 , E-mail address:rovetz85@yahoo.it

\section{Introduction}

Bromocriptine $(\mathrm{Br})$ and Cabergoline $(\mathrm{Cb})$, ergot derived dopamine receptor agonists used to treat Parkinson's disease and prolactinoma, have been associated with increased risk of cardiac valve disease. The mechanism behind this association is believed to be linked to the agonism of these drugs to the serotonin receptor 5-HT present at the level of the fibroblasts of the heart valves and that the stimulation of these receptors leads to this adverse effect of proliferation of fibroblasts and deposition of cells on the surface of valves causing retraction and fibrosis [1]. These fibrotic changes cause thickening, retraction and stiffening of the valves with consequent incomplete leaflet closure and relevant regurgitation. Here we present a case of $\mathrm{Br}$ and $\mathrm{Cb}$ induced symptomatic severe mitral regurgitation.

\section{Case Report}

A 56-year-old man was admitted to our department for acute heart failure. From the medical history emerged a prolactin-secreting pituitary adenoma, treated surgically several times and followed by radiotherapy with recidivism, hypoadrenocorticism withdrawal of replacement therapy in pan hypopituitarism, with recent hospitalizations for pleuropneumonia, pericardial effusion and bilateral pleural effusions. Treatment consisted of $\mathrm{Br} 5 \mathrm{mg}$ twice daily for 12 years and then the dosage was reduced to 2,5 $\mathrm{mg}$ three times a day for 11 years; then it has been replaced by $\mathrm{Cb} 0,5 \mathrm{mg}$ once daily for 6 months. At the hospitalization, the patient presented with dyspnea at rest and orthopnea (NYHA class IV). The physical examination was notable for increased jugular venous pressure, bilateral rales, and edema in both legs. On auscultation, a gallop rhythm and a 2/6 pan systolic murmur radiating to the axilla were noted. The blood pressure was $110 / 70 \mathrm{mmHg}$, heart rate was regular with $120 \mathrm{bpm}$, and temperature was $39^{\circ} \mathrm{C}$. ECG showed sinus tachycardia, without significant alterations of ventricular repolarization. Blood tests showed elevated C-reactive protein $(355 \mathrm{ng} / \mathrm{mL})$, high values of D-Dimer $(2532$ $\mathrm{ng} / \mathrm{mL})$ and elevated NTpro BNP (2030 pg/ml). A chest radiograph showed mild cardiomegaly and signs of acute pulmonary edema and bilateral pleural effusions. The chest CT was negative for pulmonary embolism. The pleural fluid was then drained by thoracentesis and the cytological examination had documented reactive inflammatory liquid. During the hospitalization, sudden worsening of hemodynamic compensation occurred with hypercapnic respiratory acidosis $(\mathrm{pH} 7.2, \mathrm{pCO} 260$ $\mathrm{mmHg}$ ). The patient was urgently transferred to the intensive care unit for ventilatory and cardiovascular support needed for a cardiogenic shock setting. Transthoracic echocardiography showed a not dilated left ventricle with normal global systolic function and a mild dilated and hypokinetic right ventricle with pulmonary arterial hypertension. Mild valve tricuspid valve regurgitation and venous congestion. Severe mitral regurgitation has been revealed through thickened, retracted mitral leaflets with incomplete coaptation (Fig. 1, Fig. 2). The excursion of the mitral leaflets was severely impaired. Since there was no commissural or chordal fusion, a rheumatic cause was unlikely. The patient has undergone to coronary angiography demonstrating normal coronary arteries and a Intra Aortic Balloon Pump was started. In view of the worsening clinical condition, the patient was undergone to a brain computed tomography scan that was negative for bleeding lesions, and showed the presence of 2 hyper dense nodules related to the known residual macro 

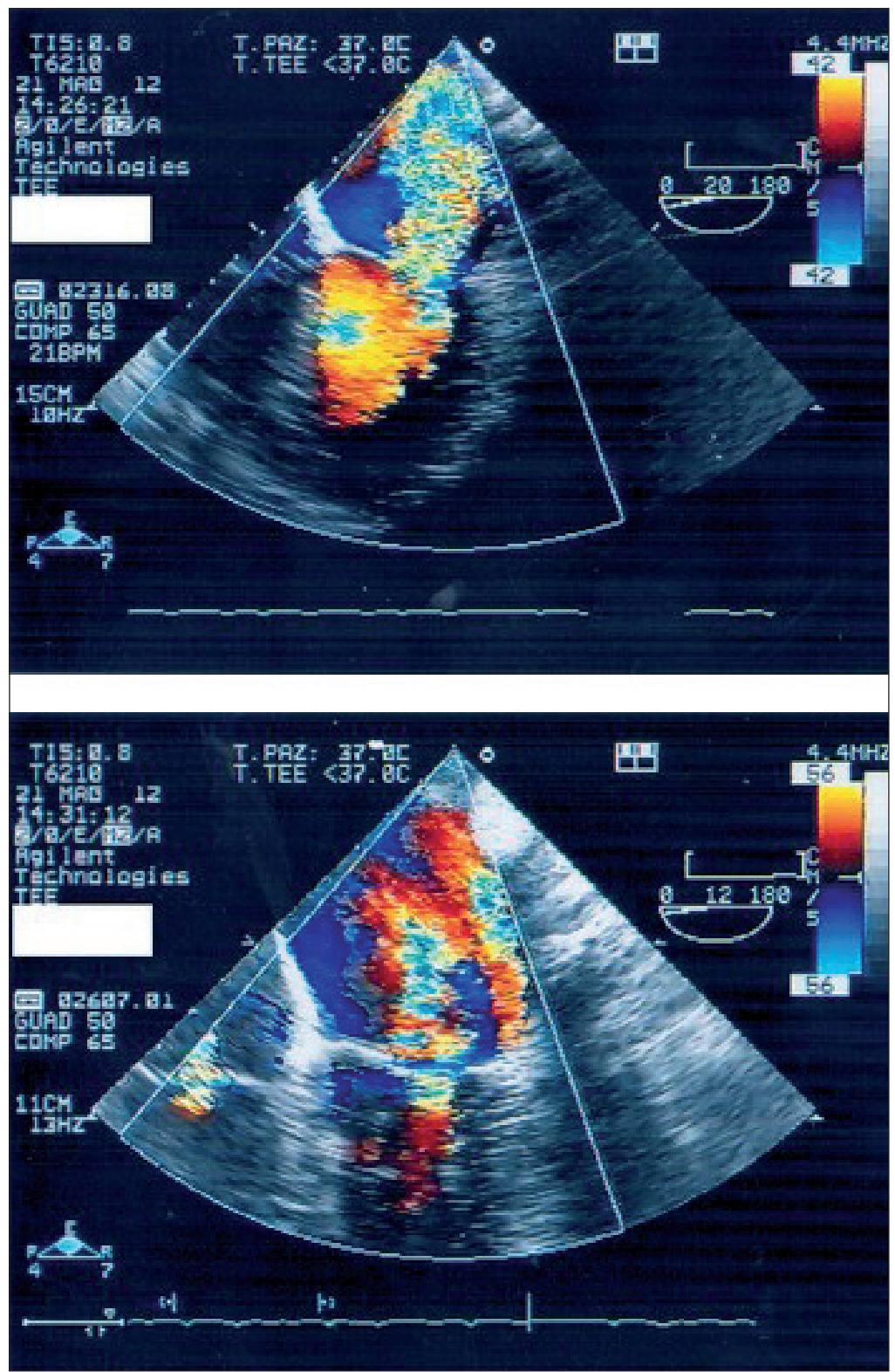

Figure 1. - Transesophageal echocardiography in four chambers views show severe mitral regurgitation.

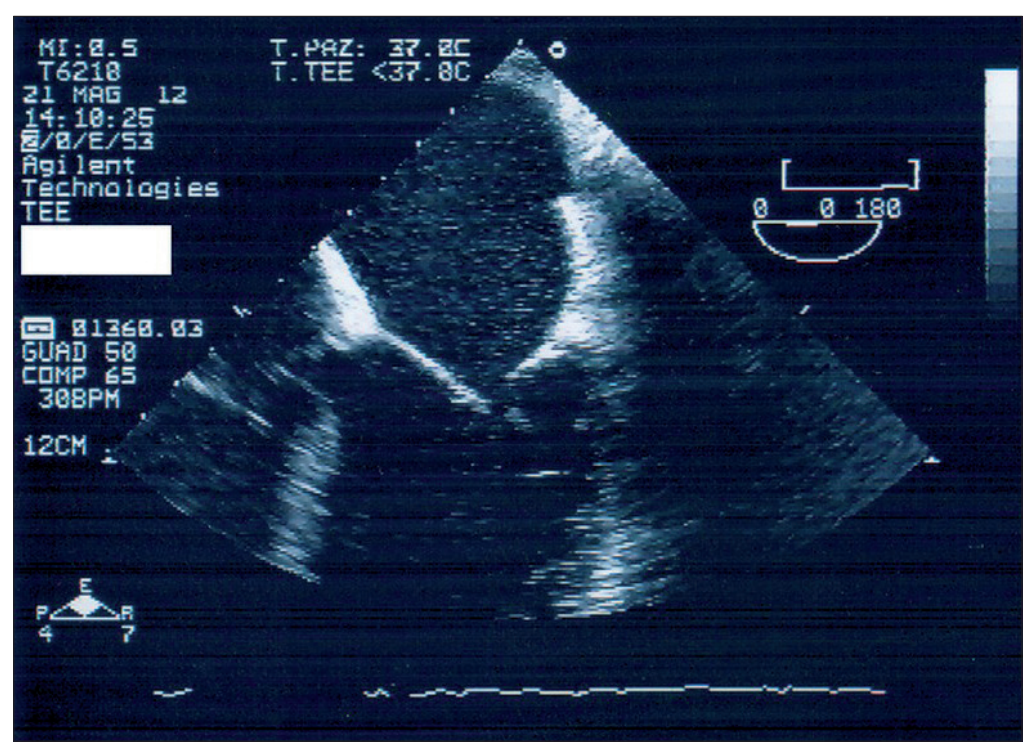

Figure 2. - Transesophageal ecocardiographic zoom on lack of coaptation of the thickened mitral leaflets. adenoma. Given the persistence of heart failure, despite pharmacological and mechanical therapy and the persistence of severe mitral valve regurgitation, the patient underwent a valve replacement with mechanical prostheses. The macroscopic examination of the valve replaced documented the presence of multiple areas of valve atherosclerosis with micro calcifications. After surgery the patient's condition improved and he was asymptomatic at discharge in good hemodynamic compensation. Echocardiographic control after surgery excluded the presence of pericardial effusion, while mild pleural effusion persisted bilaterally. During the hospitalization $\mathrm{Cb}$ has been stopped. Given the absence of other possible causes, this drug is most likely due to the development of valve disease in this patient. In the next months the patients remained healthy and was treated with steroid and anti-inflammatory non steroidal agents.

\section{Discussion}

$\mathrm{Br}$, a dopamine receptor-2 agonist used to treat prolactinomas, has been associated with cases of cardiopulmonary fibrosis [2] and valve diseases [1] in patients with Parkinson's disease. Recently the use of this drug was questioned, after the evidence of increased risk of valve regurgitation $[1,3]$. Ergotderived dopamine agonist, and especially $\mathrm{Cb}$, are efficacious and well-tolerated drugs in the treatment of prolactinoma by reducing both hyperprolactinemia and pituitary adenoma volume. BR and $\mathrm{CAB}$ are used in different settings at different doses. In patients with Parkinson's disease, the usual daily dose ranges from 2 to $6 \mathrm{mg}$, whereas in hyperprolactinemia, the weekly dose ranges from 0.25 to $3.5 \mathrm{mg}$. So far, fibrotic reactions and valve heart disease due to the use of ergot dopamine agonists have been reported almost exclusively in patients with Parkinson's disease and thus could be related to age, dosage, or both. Our patient was treated initially with $10 \mathrm{mg}$ of $\mathrm{Br}$ daily for 12 years, followed by $7,5 \mathrm{mg}$ daily for 11 years and only in the last six months had taken $\mathrm{Cb} 0,5 \mathrm{mg}$ daily. Given the time course and the absence of any other offending agent, we conclude that $\mathrm{Br}$ and $\mathrm{Cb}$ were most likely responsible for the development of valve heart disease in this patient.

The incidence of valve damage due to the cumulative dose of $\mathrm{Br}$ and $\mathrm{Cb}$ is not well established. Boguszewski et al., comparing the effects of $\mathrm{Cb}$ and $\mathrm{Br}$, have documented that both drugs showed 
higher prevalence of trace and mild tricuspid or mitral regurgitation, but these findings were not clinically significant [4]. Also, Gu et al. have stated that long-term, low-dose dopamine agonist therapy rarely causes cardiac valve disease [5]. Studies conducted by Tan et al. demonstrated that $\mathrm{Br}$ use was associated with an increased risk of developing valve heart disease, which occurred in a cumulative dose-dependent manner [6]. Horvath et al. reported pluri valve regurgitation in a patient taking $\mathrm{Cb}$ for 20 months, with stepwise increases in the dosage from $2 \mathrm{mg}$ to 4 $\mathrm{mg}$ per day [7]. Pinero described another patient was treated initially with $2 \mathrm{mg}$ of $\mathrm{CAB}$ daily; he subsequently received an additional $2 \mathrm{mg}$ daily, starting at the beginning of the second month. The serious adverse effect has been observed at the end of the fourth month of treatment [8]. Delgrado et al. described how the long-term therapy with dopamine agonists in patients with prolactinoma is associated with an increased prevalence of valve calcifications. However, these structural changes were not accompanied by an increased prevalence of valve dysfunction [9]. In some clinical trials, the absence of valve lesions could be due to short follow up. It is true that the doses of $\mathrm{Br}$ and $\mathrm{Cb}$ used in hyperprolactinemia are considerably lower than those used in Parkinson's disease [3], so it would be reasonable to assume a lower risk of valve lesions. However, higher doses of $\mathrm{Br}$ and $\mathrm{Cb}$, as in our patient, similar to those used in patients with Parkinson's disease, have been used in treating resistant hyperprolactinemia associated with giant prolactinomas [4]. In such cases, the risk of valve disease may be greater. These drugs have high affinity for 5- $\mathrm{HT}_{2 \mathrm{~B}}$ receptors located on heart valves. Surgically removed heart valves from patents with Parkinson's disease not only show retraction and stiffening, resulting in incomplete leaflet coaptation and regurgitation, but also distinctive histopathological changes, including fibroblast proliferation and deposition of cellular myxoid matrix on the valve surfaces [10]. Given that all these drugs have agonistic effects on $5-\mathrm{HT}_{2 \mathrm{~B}}$ receptors, it is tempting to assume that the histopathological changes are mediated by serotoninergic agonistic activity on the cardiac valve $5-\mathrm{HT}_{2 \mathrm{~B}}$ receptors $[2,11$, 12]. Some studies have evaluated the association between valve regurgitation and the use of $C A B$ in patients with prolactinoma [13-18] and they have shown that clinically important valve regurgitation was significantly increased in patients taking ergotderived dopamine receptor agonists, but not in patients taking non-ergot-derived dopamine agonist. In contrast to $\mathrm{CAB}$, evidence-based information about a possible profibrotic effect of BR in prolactinoma patients is extremely limited. Atanaska et al. have proved that long-term treatment with $\mathrm{CAB}$ and $\mathrm{BR}$ seems not to be associated with an increased risk of clinically significant valve disease but possible subclinical lesions should be expected [19]. These data should prompt more careful echocardiographic follow-up studies in patients with prolactinoma treated with $B R$ and $C A B$ or other ergot-derivative drugs. Prospective follow-up studies of these patients are underway and will establish how heart valve changes progress and if they are reversible when patients are switched to a non-ergot agonist.

\section{Conclusion}

This case shows severe valve pathology, probably as a result of long term and high exposure to BR and then to $\mathrm{CAB}$. Agonists of $5-\mathrm{HT}_{2 \mathrm{~B}}$ serotonin receptors produce structural changes in heart valves that result in regurgitation. Prescribers need to be aware of the risk of cardiac valve diseases associated with the use of ergot-derived dopamine agonists and young patients receiving low-dose of BR or $\mathrm{CAB}$ therapy for hyperprolactinemia should be aware of the potential risk of fibrotic side effects. Patients being treated with these drugs should be carefully examined with echocardiography to prevent the progression of early changes and they should be warned about the potential adverse events. Furthermore, there is a need for larger studies and with longer duration of follow up with echocardiographic assessment to establish how heart-valve changes progress and if they are reversible when patients are switched to a non-ergot agonist.

\section{Riassunto}

La bromocriptina e la cabergolina, derivati dell'ergotamina, sono agonisti dei recettori dopaminergici usati per curare il morbo di Parkinson e prolattinomi. Essi sono stati associati ad un aumentato rischio di patologia valvolare. Vi presentiamo un caso di insufficienza mitralica iatrogena sintomatica di grado severo causata da questi farmaci.

\section{References}

1. Fitzgerald LW, Burn TC, Brown BS, et al. Possible role of valvular serotonin 5-HT (2B) receptors in the cardiopathy associated with fenfluramine. Mol Pharmacol 2000; 57: 75-81.

2. Dhawan V, Medcalf P, Stegie F, et al. Retrospective evaluation of cardio-pulmonary fibrotic side effects in symptomatic patients from a group of 234 Parkinson's disease patients treated with cabergoline. J Neural Transm 2005 May; 112 (5): 661-8.

3. Schade R, Andersohn F, Suissa S, et al. Dopamine agonists and the risk of cardiac-valve regurgitation. $N$ Engl $J$ Med 2007 Jan 4; 356 (1): 29-38.

4. Boguszewski CL, dos Santos CM, Sakamoto KS, Marini LC, de Souza AM, Azevedo M. A comparison of cabergoline and bromocriptine on the risk of valvular heart disease in patients with prolactinomas. Pituitary 2012 Mar; 15 (1): 44-9.

5. Gu H, Luck S, Carroll PV, et al. Cardiac valve disease and low-dose dopamine agonist therapy: an artefact of reporting bias? Clin Endocrinol (Oxf) 2011 May; 74 (5): 608-10.

6. Tan LC, Ng KK, Au WL, et al. Bromocriptine use and the risk of valvular heart disease. Mov Disord 2009 Feb 15; 24 (3): 344-9

7. Horvath J, Fross RD, Kleiner-Fisman G, et al. Severe multivalvular heart disease: a new complication of the ergot derivative dopamine agonists. Mov Disord 2004; 19 : 656-662.

8. Pinero A, Marcos-Alberca P, Fortes J. Cabergoline-related severe restrictive mitral regurgitation. $N$ Engl J Med 2005; 353: 1976-1977.

9. Delgado V, Biermasz NR, van Thiel SW, et al. Changes in heart valve structure and function in patients treated with dopamine agonists for prolactinomas, a 2-year follow-up study. Clin Endocrinol (Oxf) 2012 Jul; 77 (1): 99-105. 
10. Van Camp G, Flamez A, Cosyns B, et al. Treatment of Parkinson's disease with pergolide and relation to restrictive valvular heart disease. Lancet 2004; 363: 1179-83.

11. Horvath J, Fross RD, Kleiner-Fisman G, et al. Severe multivalvular heart disease: a new complication of the ergot derivative dopamine agonists. Mov Disord 2004 Jun; 19 (6): 656-62.

12. Pinero A, Marcos-Alberca P, Fortes J. Cabergoline-related severe restrictive mitral regurgitation. $N$ Engl J Med 2005 Nov 3; 353 (18): 1976-7.

13. Lancellotti P, Livadariu E, Markov M, et al. Cabergoline and the risk of valvular lesions in endocrine disease. Eur $J$ Endocrinol 2008; 159: 1-5.

14. Bogazzi F, Buralli S, Manetti L, et al. Treatment with low doses of cabergoline is not associated with increased prevalence of cardiac valve regurgitation in patients with hyperprolactinaemia. Int J Clin Pract 2008; 62: 1864-9.

15. Kars M, Delgado V, Holman ER, et al. Aortic valve calcification and mild tricuspid regurgitation, but no clinical heart disease after 8 years of dopamine agonist therapy for prolactinoma. J Clin Endocrinol Metab 2008; 93: 3348-56.

16. Colao A, Galderisi M, Di Sarno A, et al. Increased prevalence of tricuspid regurgitation in patients with prolactinomas chronically treated with cabergoline. J Clin Endocrinol Metab 2008; 93: 3777-84.

17. Vallette S, Serri K, Rivera J, et al. Longterm cabergoline therapy is not associated with valvular heart disease in patients with prolactinomas. Pituitary 2009; 12: 153-7.

18. Wakil A, Rigby A, Clark A, Atkin S. Low dose cabergoline for hyperprolactinaemia is not associated with clinically significant valvular heart disease. Eur J Endocrinol 2008; 159: R11-4.

19. Atanaska Elenkova, Rabhat Shabani, Krassimir Kalinov, Sabina Zacharieva. Increased prevalence of subclinical cardiac valve fibrosis in patients with prolactinomas on long-term bromocriptine and cabergoline treatment. Eur J Endocrinol 2012; 167 (1): 17-25. 